University of Nebraska - Lincoln

DigitalCommons@University of Nebraska - Lincoln

Jay F. Storz Publications

Papers in the Biological Sciences

$6-2000$

\title{
Social structure of a polygynous tent-making bat, Cynopterus sphinx (Megachiroptera)
}

Jay F. Storz

University of Nebraska - Lincoln, jstorz2@unl.edu

Hari Bhat

National Institute of Virology, Pune, 411 001, India

Thomas H. Kunz

Boston University, 5 Cummington Street, Boston, MA

Follow this and additional works at: https://digitalcommons.unl.edu/bioscistorz

Part of the Genetics and Genomics Commons

Storz, Jay F.; Bhat, Hari; and Kunz, Thomas H., "Social structure of a polygynous tent-making bat, Cynopterus sphinx (Megachiroptera)" (2000). Jay F. Storz Publications. 30.

https://digitalcommons.unl.edu/bioscistorz/30

This Article is brought to you for free and open access by the Papers in the Biological Sciences at DigitalCommons@University of Nebraska - Lincoln. It has been accepted for inclusion in Jay F. Storz Publications by an authorized administrator of DigitalCommons@University of Nebraska - Lincoln. 
Published in Journal of Zoology 251:2 (June 2000), pp. 151-165; doi 10.1111/j.1469-7998.2000.tb00600.x

Copyright $\odot 2000$ The Zoological Society of London; published by Blackwell Publishing.

Used by permission. http://www3.interscience.wiley.com/journal/118535410/home

Accepted for publication June 2, 1999.

\title{
Social structure of a polygynous tent-making bat, Cynopterus sphinx (Megachiroptera)
}

\author{
Jay F. Storz, ${ }^{1}$ Hari R. Bhat, ${ }^{2}$ and Thomas H. Kunz ${ }^{1}$ \\ ${ }^{1}$ Department of Biology, Boston University, 5 Cummington Street, Boston, MA 02215, USA \\ ${ }^{2}$ National Institute of Virology, Pune, 411 001, India; present address: 107 Awanti, OPP: \\ Kamala Nehru Park, Erandawana, Pune, 411 004, India
}

\begin{abstract}
The social structure of an Old World tent-making bat Cynopterus sphinx (Megachiroptera), was investigated in western India. A combination of census and mark-recapture data over 2 years (1996-98) was used to infer the form of the mating system, compositional stability of social groups and mode of new social group formation. The breeding population of C. sphinx was subdivided into diurnal roosting colonies, each of which contained one to five discrete roosting groups and often one or more solitary bats in adjacent roosts. Bats most frequently roosted in stem tents constructed in the flower/fruit clusters of the kitul palm Caryota urens. Temporal variation in social structure was assessed using visual census data for a subset of the study population over 3 years (199598) spanning six consecutive reproductive periods. The sex and age composition of diurnal roosting groups indicated a polygynous harem-forming mode of social organization, as groups invariably contained a single adult male, 1-37 reproductive females and their dependent young ( $n=33$ harems). Harem size averaged 6.1 adults in the wet season $(n=19, \mathrm{SD}=3.5)$ and 13.6 adults in the dry season $(n=14, \mathrm{SD}=8.5)$. The same harem social configuration was maintained year-round, despite a high degree of synchrony and seasonality in the timing of reproduction. Juveniles of both sexes dispersed after weaning and sexually immature bats were never present in harems at the time of parturition. Adult females often remained associated as roostmates from one parturition period to the next, and group cohesion was unaffected by turnover of harem males. Adult females frequently transferred among roosts within the same colony, and harems underwent periodic fissions and fusions. The founding of new harems most often resulted from the fissioning of previously cohesive harems within the same colony. However, some harems contained disproportionate numbers of yearling females, indicating that new groups are also founded by nulliparous females of the same age cohort. A significant degree of heterogeneity in age composition among harems was revealed in the 1998 dry season, but was unrelated to age-stratification of tent roosts. Although formation of new harems may be non-random with respect to age composition of the founders, founding events are not restricted to newly created tents and often involve recolonization of previously occupied roosts.
\end{abstract}

\section{Introduction}

Within the constraints imposed by ecological circumstance and phylogenetic history, the evolution of animal mating systems is driven by the interplay between male and female reproductive strategies (Davies, 1991). In mammals, the level of aggregation among reproductive females is conventionally regarded as a primary determinant of the mating system, since the reproductive strategies of males are largely adapted to spatial and temporal patterns of female dispersion (Bradbury \& Vehren- camp, 1977; Emlen \& Oring, 1977; Clutton- Brock, 1989b). When the spatial dispersion of females is highly clumped, a small fraction of the adult male population will be more likely to succeed in monopolizing opportunities for mating. In such circumstances, the potential for polygyny is maximized when: (1) the breeding population of females is subdivided into discrete groups, (2) female groups are stable in composition through time, (3) female groups are economically defendable (so that reproductive access can be monopolized by a single male), (4) male breeding tenure spans multiple female generations. In socially struc- 
tured populations, the degree of polygyny is probably the single most important determinant of the genetically effective population size (Chesser et al., 1993; Nunney, 1993) and the comparative opportunity for selection in males and females (Wade \& Arnold, 1980; Clutton-Brock, 1988, 1991).

Regardless of whether the genetic structure of a population constitutes a primary cause or a secondary consequence of sociality, the delineation of breeding units according to social affiliations has important implications for the course of microevolutionary events. The subdivision of populations into stable, behaviorally cohesive kin groups is conducive to the evolution of cooperative and altruistic behaviors and facilitates rapid rates of microevolutionary change in terms of shifts in allelic frequencies (Storz, 1999). Social structure also influences the distribution of reproductive success in males and females and thus has consequences for the intensity of sexual selection, the evolution of life-history differences between the sexes, and parental investment in male and female offspring (Clutton-Brock, 1988, 1991). To gain a complete understanding of the social structure of a given species in evolutionary terms, it is necessary to determine how the outcome of reproductive strategies influences population structure and the opportunity for selection.

The social systems of bats exhibit an extraordinary diversity of form and function (Bradbury, 1977b; Wilkinson, 1987; McCracken \& Wilkinson, in press). Despite the variation in social structure related to differences in roosting and foraging ecology, several neotropical bat species exhibit consistent trends with regard to male mating strategies (Wilkinson, 1987; McCracken \& Wilkinson, in press). Female gregariousness at diurnal roosting sites has apparently facilitated polygynous mating systems in an ecologically diverse array of species. In each case, the apparent skew in male reproductive access results from the direct and/or indirect defense of female groups in roosts such as the buttress cavities of large trees (Bradbury \& Emmons, 1974; Bradbury \& Vehrencamp, 1976), tree cavities (Morrison, 1979; Wilkinson, 1985), foliage roosts (Kunz \& McCracken, 1996; Storz et al., 2000), and cavities or indentations in cave ceilings (McCracken \& Bradbury, 1981; Kunz, August \& Burnett, 1983; Williams, 1986). However, superficial similarities in the social mating systems of these species often belie differences in the size and compositional stability of social groups (e.g, Bradbury \& Emmons, 1974; Bradbury \& Vehrencamp, 1976). Thus, considerable variation within and among species should be expected with regard to population structure and scope for the evolution of sex differences.

In this study we investigated social dispersion and group dynamics in a natural population of the shortnosed fruit bat Cynopterus sphinx (Megachiroptera) to determine how male and female reproductive strategies have influenced population structure. Specifically, we sampled the sex and age composition of social groups and used a combination of census and mark-recapture data to infer: (1) the form of the social mating system, (2) rates of adult and juvenile dispersal, (3) the mode of new social group formation.

Cynopterus sphinx is a medium-sized (40-70 g) frugivorous bat that is widely distributed across the Indomalayan region (Storz \& Kunz, 1999). Cynopterus sphinx is seasonally polyestrous, having two distinct reproductive periods per year. In peninsular India, parturition typically occurs in March-April and again in July-August. Females give birth to single pups, and can thus produce a maximum of two young per year (Krishna \& Dominic, 1983; Sandhu, 1984). Once pups are born in MarchApril, females undergo a postpartum estrus (Ramakrishna, 1947; Krishna \& Dominic, 1983; Sandhu, 1984). Females are simultaneously pregnant and lactating until pups from the March-April cohort are weaned. Following the birth of the July-August cohort, females are anestrous until October (Krishna \& Dominic, 1983; Sandhu, 1984; Sandhu \& Gopalakrishna, 1984). Cynopterus sphinx makes use of a wide variety of diurnal roosts and often alters different types of foliage to create "tents" (Goodwin, 1979; Bhat, 1994; Balasingh, Koilraj \& Kunz, 1995; Bhat \& Kunz, 1995; Storz et al., 2000). In western India, for example, C. sphinx chews and severs the strings of dense, pendulous flower/fruit clusters of the kitul palm Caryota urens to create enclosed, bell-shaped roosting spaces (Bhat \& Kunz, 1995). Tent-making behavior has been inferred among several neotropical fruit bats of the family Phyllostomidae (suborder Microchiroptera), but among paleotropical fruit bats of the family Pteropodidae (suborder Megachiroptera), tentmaking behavior has been reported only in the genus Cynopterus (Kunz, Fujita et al., 1994). Tent-making in C. sphinx is an exclusively male behavior (Balasingh et al., 1995). Tents attract groups of reproductive females that a single male then defends as a harem. Similarly, among several members of the family Phyllostomidae (Artibeus and Uroderma), polygynous mating systems appear to be linked to male defense of reproductive access to tent-roosting females (Kunz \& McCracken, 1996). In this paper we report results of one of the first in-depth studies of social structure in a megachiropteran fruit bat. Behavioral studies of the Microchiroptera, and phyllostomids in particular (reviewed in Wilkinson, 1987; McCracken \& Wilkinson, in press), provide a valuable store of comparative data to assess the causes and consequences of social structure in a phylogenetically distinct species of fruit bat.

\section{Methods \\ Study area}

This study was conducted in Pune, Maharashtra, India $\left(18^{\circ} 32^{\prime} \mathrm{N}, 73^{\circ} 51^{\prime} \mathrm{E}\right)$ over 25 months (April 1996-April 1998). Additionally, we monitored a subset of the study population over 36 months (May 1995-April 1998). Pune is located in the rain shadow of the Western Ghats at an 
elevation of c. $660 \mathrm{~m}$. The surrounding region is characterized by tropical dry deciduous vegetation interspersed with evergreen shrubs and trees. At the outset of the study we searched for day-roosting C. sphinx in a delimited area measuring c. $2.5 \mathrm{~km}$ in diameter. We searched for tents in the fronds of palms such as Borassus flabellifer (palmyra palm), Washingtonia filifera (desert palm), Sabal palmetto (palmetto palm), Livistona chinensis (Chinese fan palm), Livistona rotundifolius (Malayan fan palm), Thrinax parviflora (broom palm), Coccothrinax argentea (silver thatch palm), Corypha umbraculifera (talipot palm), Roystonea regia (Cuban royal palm), and Phoenix sylvestris (silver date palm); in the flower/fruit clusters of Caryota urens (kitul palm); and in the foliage of Polyalthia longifolia (mast tree) and Dracaena fragrans (massangeana). We also searched for roosts in artificial structures. In April 1996, 12 roosting colonies were located in the Deccan Gymkhana/Erandawana district of Pune, including several that have been monitored since 1995 as part of a long-term study. Within a single season, each colony contained 1-5 discrete roosting groups and often 1 or more solitary bats in adjacent roosts. From 1996 to 1998, 10 colonies roosted in flower/ fruit cluster tents of kitul palms ("kitul palm colonies") and 2 roosted beneath boxed window eaves of bungalows ("building colonies"). A kitul palm colony comprised all tent-roosting bats occupying a single tree, or cluster of 23 adjacent trees (Figure 1). There was often only 1 tentroosting group per colony, but in other colonies, several groups occupied different tents on the same or adjacent trees. In both situations, 1 or more solitary bats often occupied separate tents within the same colony. A building colony comprised all bats that roosted beneath adjacent window eaves on the same bungalow. In each of the 2 building colonies, the boxed window eaves were discrete compartments, separated from adjacent eaves by $3 \mathrm{~m}$. As with the kitul palm colonies, building colonies contained either a single group or several, often in association with 1 or more solitary bats. Both types of colony were outwardly similar in terms of social dispersion. The main difference was that there were more nearby roosts available in the 2 building colonies compared with the kitul palm colonies.

\section{Trapping, marking and censusing}

Complete social groups and solitary male C. sphinx were trapped in their diurnal roosts using a hoop net attached to an extensible aluminum pole. The bats were collected

Figure 1. (a) A kitul palm tree Caryota urens that housed the Mahajani colony of Cynopterus sphinx. Three flower/fruit clusters that were modified as tents (T3, T4, and T5) and occupied by bats in the 1997 wet season are indicated. Harems of C. sphinx roosting in the altered crowns of mature fruit clusters (tent T4 and tent T5) in the 1998 dry season, are shown in (b) and (c), respectively. The harem males in each tent are indicated by arrows.
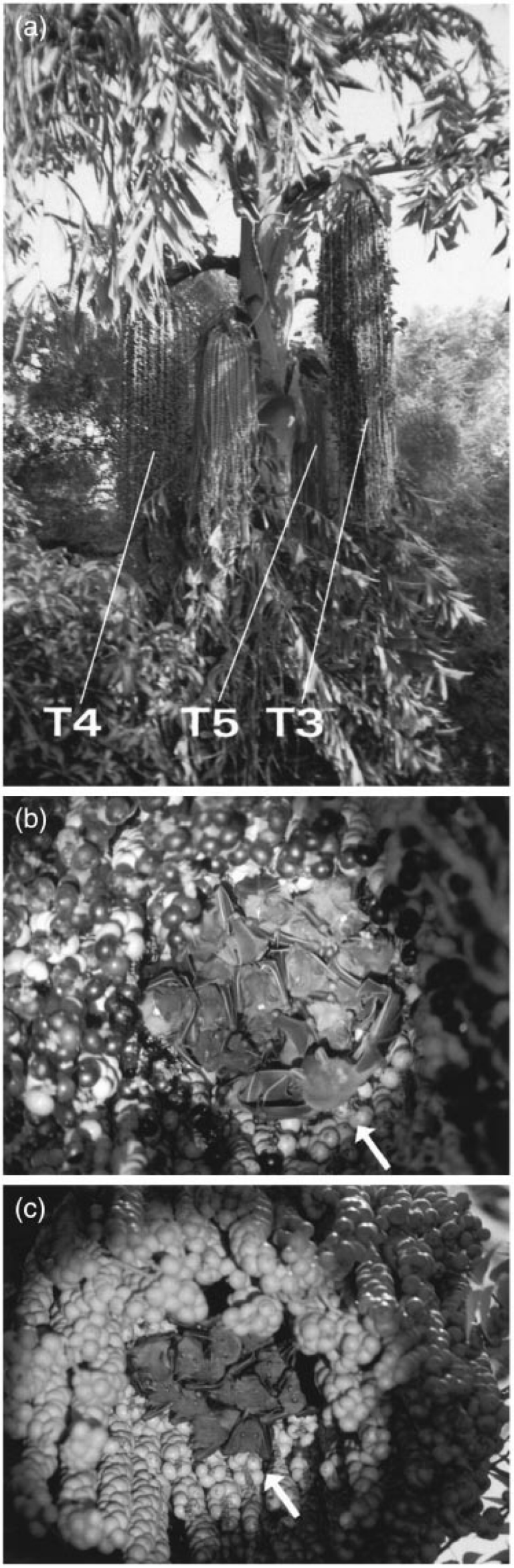
over approximately 4 weeks immediately following each of 2 annual parturition periods: March-April (dry season) and July-August (wet season). We made 2 separate dry season collections (April 9-May 8, 1996, and March 30April 28, 1998) and 1 wet season collection (July 23-August 22, 1997). Collections were made when nearly all females had given birth but pups had not been weaned.

Sex, reproductive condition, length of forearm, and body mass were recorded for each bat captured. Parity of adult females was assessed by examination of the nipples (Sandhu, 1984; Sandhu \& Gopalakrishna, 1984; Racey, 1988). Adult females were classified as nulliparous if they had not yet given birth. We distinguished between those that were primigravid (pregnant for the first time) and those that were not pregnant (but may or may not have been inseminated; Racey, 1988). Adult females were classified as primiparous if they had given birth for the first time (Sandhu, 1984; Sandhu \& Gopalakrishna, 1984).

Adults were individually marked with a numbered aluminum band (size 4.2, Lambournes, Ltd.) strung on a stainless-steel ball-chain necklace (size \#3 chain and size \#3 connector, Ball Chain Manufacturing Company, Inc.). Pups were marked with a numbered, plastic split-ring forearm band (size 2X, A. C. Hughes, Ltd.).

Females were banded on the left forearm, males on the right. To place the band around the forearm, a small incision was made in the antebrachial membrane (Kunz, 1996). Beginning in 1997, the teeth of each adult were examined and adults were classified into 6 categories based on an assessment of the degree of toothwear of the upper canines, premolars, and molars (C1-M1 toothwear; cf. Anthony, 1988; Fleming, 1988; Brooke, 1997). Bats with sharp-tipped, recurved upper canines (C1s) and unworn cheekteeth (P1-M1) were assigned the minimal score of 1; bats with the maxillary toothrow (C1-M1) worn to the gumline were assigned the maximal score of 6 . Additionally, C1s were measured to the nearest $0.1 \mathrm{~mm}$ with dial callipers, from the tip to the labial cingulum. The C1-M1 toothwear scores and $\mathrm{C} 1$ lengths were used as indices of relative age (Anthony, 1988). The strength of correlation between relative age and each of the 2 toothwear measures was assessed by scoring recaptured bats in 1998 . Finally, we took tissue biopsies from the patagial membrane of both pups and adults for the purpose of DNA analysis, the results of which will be reported elsewhere. Pups were returned to their mothers immediately after processing. All bats were held in net cages and were released at their roosts on the evening of the same day they were captured.

From April 1996 to April 1998 the roosting colonies were visually censused at 1-month intervals to monitor the dispersal of juveniles after weaning, seasonal changes in group size, the dissolution of groups and the founding of new ones. Visual censuses of tent-roosting groups were accomplished using a circular mirror, $40 \mathrm{~cm}$ in diameter, to reflect sunlight into the interior crown of the tents. Adult males were easily distinguished from females on the basis of pelage color. Adult males are a rich russet brown and the fur on the shoulders and the nape of the neck has a highly distinctive orange tint. Adult females, by contrast, are typically olive grey (Bates \& Harrison, 1997). The visual censuses permitted an accurate assessment of the distribution of social configurations (i.e., the number of groups and solitary bats per colony), but in some roosts it was not always possible to count the exact number of bats. Exact counts of every adult bat in the study population (both group members and solitary bats) were possible only in the last 2 consecutive reproductive periods, July-August 1997 and March-April 1998, when we conducted simultaneous visual censuses of roosting colonies in conjunction with trapping. Thus, data on the size and breeding sex ratio of social groups, colonies, and the study population as a whole are based on these simultaneous trapping and censusing records in 1997 and 1998.

From May 1995 to April 1998, we monitored a single colony (Mahajani) within the study area in which the size and sex-composition of each of the constituent roosting groups could be observed. During each of the monthly censuses we recorded the exact number and sex of bats that occupied a series of 5 adjacent tents over the course of 6 consecutive reproductive periods.

\section{Results}

We sampled 544 bats (42 adult males, 277 adult females, and 225 pups) over three successive reproductive periods. Thirty-three of the adults (10.3\% of adult total) were recaptured in the 1997 and 1998 collections. The breakdown by collection was as follows: 1996, six groups (six adult males, 43 adult females, and 40 pups); 1997, 14 groups and three solitary males (17 adult males, 81 adult females, and 67 pups); and 1998, 13 groups and six solitary males (19 adult males, 153 adult females, and 118 pups). The estimated percentage of the total breeding population sampled per collection was $78.4 \%$ in the 1997 wet season and $86.9 \%$ in the 1998 dry season.

\section{Social organization}

Roosting groups invariably contained a single adult male roosting with one or more adult females (Table 1), referred to here as harems (sensu Bradbury, 1977b; McCracken \& Wilkinson, in press). The year-round average harem size determined from simultaneous capture and census records (1997-98) was 9.9 adults $(n=33$ harems, $\mathrm{SD}=6.0$, range 2-38). All harems were censused and monitored continuously prior to trapping, so even in the few cases in which one or more bats escaped our capture attempts, we could be confident in our assessment of the exact number and sex ratio of the bats in each group (Table 1). Solitary bats invariably proved to be adult males 
Table 1. Collections of Cynopterus sphinx harems and satellite males in Pune, India, 1996-98.

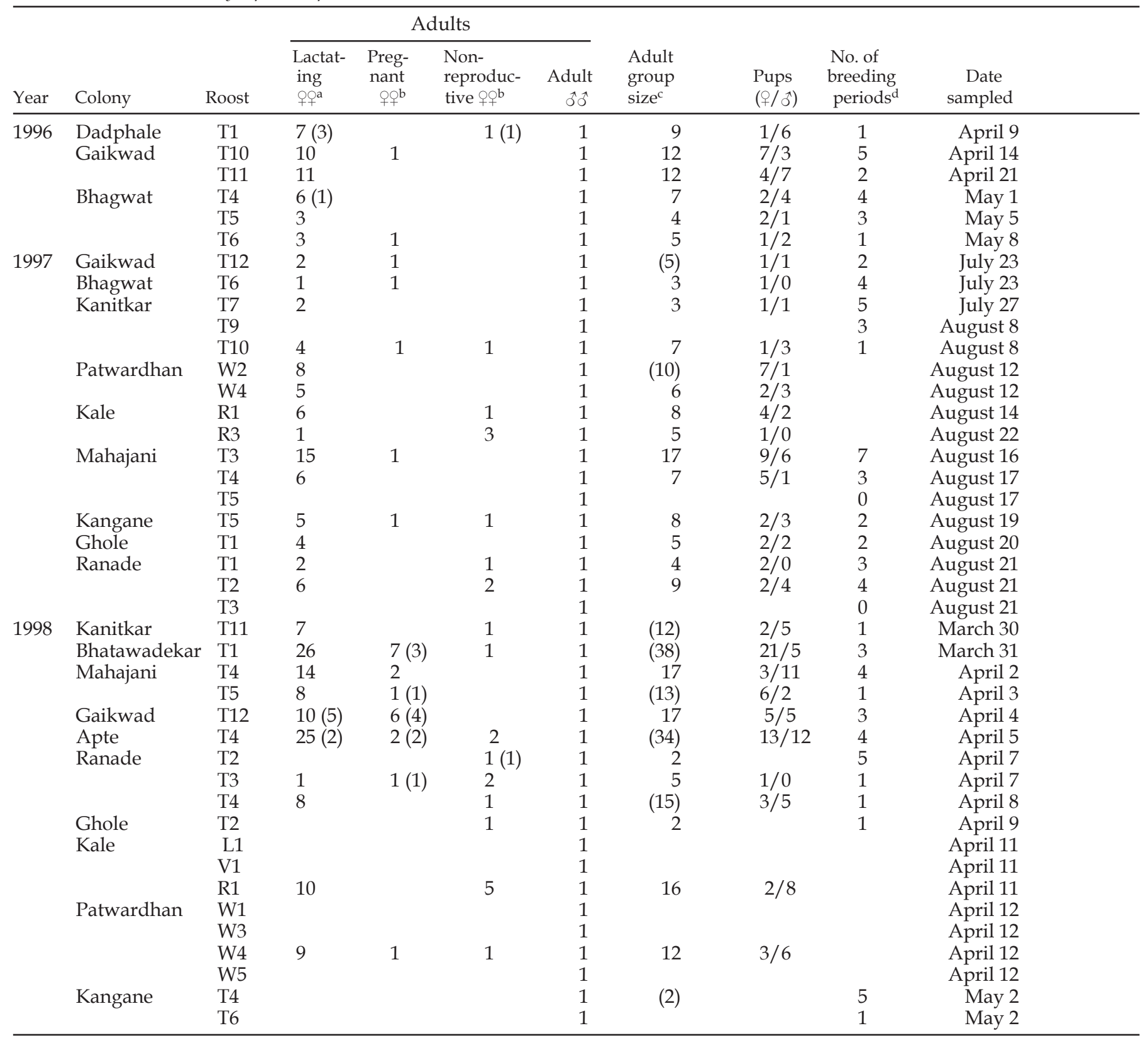

$(n=544$ individuals $)$

a Number of primiparous females contributing to the total is given in parentheses.

${ }^{b}$ Number of nulliparous females contributing to the total is given in parentheses.

${ }^{\mathrm{c}}$ If one or more bats escaped capture, the total group size is given in parentheses.

$\mathrm{d}$ The maximum potential number of parturition periods that have elapsed (at the time of sampling) since the tent roost was originally colonized. A value of zero indicates that the tent-roost had been occupied previously only by a single male. A value of one indicates that the resident harem was sampled immediately following the first parturition period that occurred in that particular tent-roost (see text for details).

and always occupied roosts adjacent to those with harems. We found no evidence of bachelor groups such as those documented in neotropical bat species (e.g. Artibeus jamaicensis, Kunz, August et al., 1983; Phyllostomus hastatus, McCracken \& Bradbury, 1981; Carollia perspicillata, Williams, 1986).

Our observations that tent-making is an exclusively male behavior agree with those of Balasingh et al. (1995).
If occupied at all, tents that were in the construction phase were invariably occupied by a single adult male. Judging from the daily accumulation of chewed and severed flower stems on the ground beneath such tents, nearly all the work in tent construction took place several weeks or months before the arrival of females. Our observations indicate that kitul palm tents remain suitable as diurnal roosts for a maximum of 4 years. They are abandoned 
once the cluster starts to wither and the fruits drop. At any one time, a given tree will typically have one to five flower/fruit clusters (Figure 1a), although only one new flower cluster will become available for tent construction per season. Thus, when two or more tents are occupied in the same tree, the potential discrepancy in age (time since founding) between resident harems varies between 1 and 4 years.

\section{Morphological variation}

The two measures of overall body size, length of forearm and body mass, both conformed to normal distributions (Kolmogorov-Smirnov one-sample test: $D_{\mathrm{n}}=$ $0.033_{286^{\prime}}, P>0.05$, and $D_{\mathrm{n}}=0.033_{257}, P>0.05$, respectively) and no inequality of variances was evident between the sexes (Bartlett's test: $\chi^{2}{ }_{1}=0.379, P>0.05$ and $\chi_{1}^{2}=0.262$, $P>0.05$, respectively). Data for recaptured bats were not included, nor were body mass data for pregnant females. No statistically significant size dimorphism in body size was evident (Table 2). Because body size may be expected to influence female mate choice and/ or the outcome of male-male competition, we tested for size differences between satellite males and harem males. No significant size differences were evident in either year in which satellite males were sampled (Table 3). Likewise, we detected no significant correlation between male forearm length and harem size (1996, Spearman's $r_{\mathrm{s}}=0.232, n=6, P>0.05 ; 1997$, Spearman's $r_{\mathrm{s}}=0.135, n=14, P>0.05 ; 1998$, Spearman's $r_{\mathrm{s}}=70.011, n$ $=13, P>0.05$ ) or male body mass and harem size (1996, Spearman's $r_{\mathrm{s}}=70.232, n=6, P>0.05 ; 1997$, Spearman's $r_{\mathrm{s}}=70.329, n=14, P>0.05 ; 1998$, Spearman's $r_{\mathrm{s}}=0.191, n$ $=13, P>0.05)$.

\section{Relative age estimates}

Nulliparous and primiparous females invariably received a C1-M1 toothwear score of one and had significantly higher C1 measurements than parous females (199798, Mann-Whitney $U$-test, $U_{\mathrm{n} 1 \mathrm{n} 2}=119.0_{19: 180}, P<0.001$ ). The relative age rankings of females based on $\mathrm{C} 1$ length and the C1-M1 toothwear score were strongly correlated (Spearman's $r_{\mathrm{s}}=0.930, n=199, P<0.001$ ). The validity of toothwear as an index of relative age was demonstrated by a strong correlation in the rank-order of $\mathrm{C} 1$ measurements among recaptured adult females between the 1997 and 1998 collections (Spearman's $r_{\mathrm{s}}=0.936, n=28, P<0.001$ ). The reordering of ranks between collections was slightly more pronounced for the C1-M1 toothwear score (Spearman's $\left.r_{\mathrm{s}}=0.873, n=28, P<0.001\right)$, as 19 of 28 individuals remained unchanged in their category assignments and the remainder shifted into the next higher age category.

We detected no significant differences in $\mathrm{C} 1$ ranks between satellite males and harem males in either season (1997, Mann-Whitney $U$-test, $U_{\text {n1:n2 }}=6.0_{3: 14}, P=0.058$; $\left.1998, U_{\mathrm{n} 1: \mathrm{n} 2}=40.5_{6: 13}, P=0.895\right)$. Likewise, we detected no significant correlation between C1 rank and harem size (1997, Spearman's $r_{\mathrm{s}}=0.159, n=14, P>0.05 ; 1998$, Spearman's $\left.r_{\mathrm{s}}=-0.304, n=13, P>0.05\right)$.

\section{Variation in social organization}

The same harem social configuration was maintained year-round, through each of two annual reproductive periods. However, there was considerable variation in the size and dispersion of harems between the wet and dry season reproductive periods. The distribution of harem sizes (Figure 2) illustrates that harems in the 1997 wet

Table 2. Comparison of morphological variables between adult male and female C. sphinx. Body mass data for pregnant females are not included.

\begin{tabular}{llccrrr}
\hline Variable & Sex & Mean & SD & $n$ & $t$ & $P$ \\
\hline Length of forearm (mm) & M & 74.3 & 2.1 & 37 & 1.424 & 0.155 \\
Body mass (g) & F & 73.7 & 2.0 & 249 & & 0.832 \\
& M & 59.8 & 3.8 & 37 & 0.213 & \\
\hline
\end{tabular}

Table 3. Comparison of morphological variables between harem males (HM) and satellite males (SM) in each of two collections

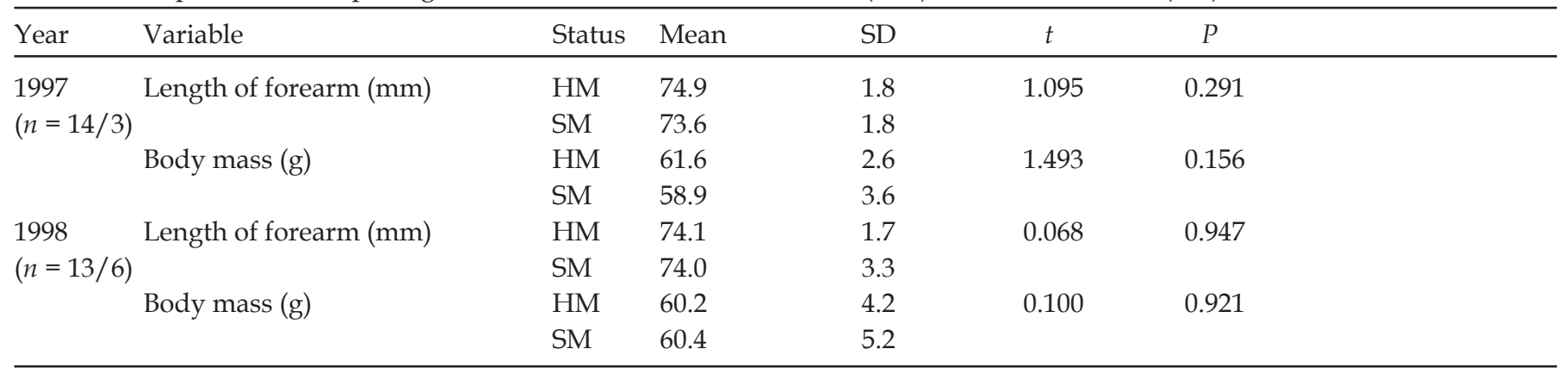




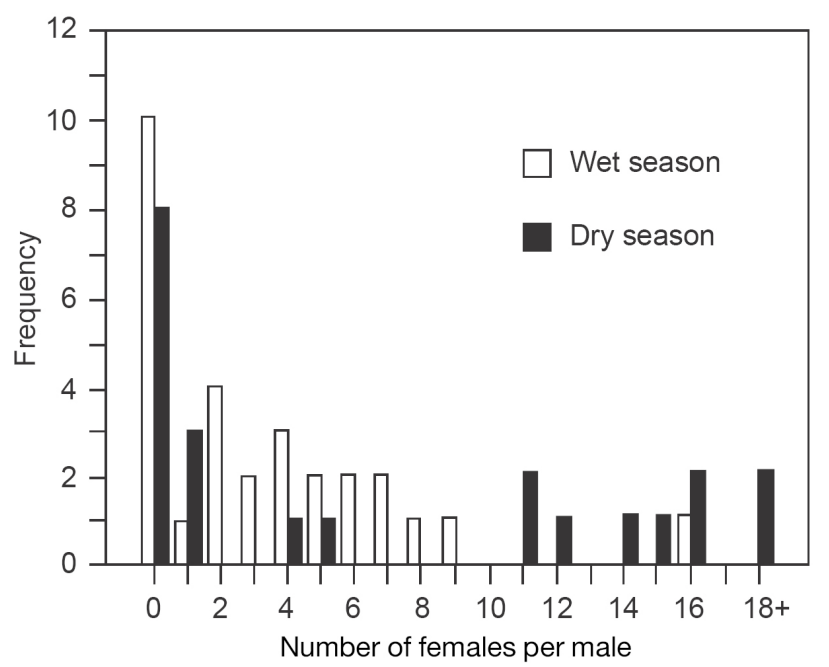

Figure 2. The number of adult females per male in the 1997 wet season and 1998 dry season.

season were more-or-less evenly distributed among group sizes of $<10$, whereas the harems in the 1998 dry season were far more variable in size. The dispersion of adult females within the study area differed substantially from Poisson expectations in both seasons. In July- August 1997, there were 19 harems in the study area, each containing an average of 6.1 sexually mature adults $(\mathrm{SD}=3.5$, range 2-17). In March-April 1998, there were 14 harems in the study area, each containing an average of 13.6 sexually mature adults ( $\mathrm{SD}=8.5$, range 2-38; Table 4). Compared to the 1997 wet season, the total breeding population in the 1998 dry season was 1.6 times larger, the average colony size was 1.8 times larger, and the average harem size was 2.3 times larger (Table 4). Considering the 10 colonies containing one or more harems in both 1997 and 1998, and the 16 roosts occupied in both seasons, Wilcoxon signedrank tests for matched-pairs indicated statistically significant increases in the size of harems in the 1998 dry season reproductive period (mean increase $=7.0$ adults, $\mathrm{SD}$
$=10.9, Z=2.295, P=0.022)$, but not in the overall size of colonies (mean increase $=7.7$ adults, $S D=12.7, Z=1.543$, $P=0.123)$. The seasonal discrepancy in the overall size of the study population was attributable to the disappearance of a large fraction of the adult female population during the wet season reproductive period, and suggests that many adult females in the study population undergo a seasonal shift in their use of roosts. This same pattern was observed in the Mahajani colony (Figure 1) over 36 months. Considering 2-month blocks corresponding to each of six consecutive reproductive periods (February-March and July-August), the total size of the Mahajani colony in the dry season was 1.7 times larger than in the wet season (mean increase $=15.0$ adults, $S D=16.5$; Mann-Whitney $U$ test, $U=9.0, P=0.050)$ and the average harem size was 1.8 times larger (mean increase $=6.8$ adults, $\mathrm{SD}=3.8 ; U=9.0$, $P=0.043$ ). The long-term census data from this colony also indicate substantial variation in harem size on a month-tomonth basis (Figure 3). The mean size of the entire colony over the 36 month census was 29 adults (median $=30, C V=$ 32.5 ), while the mean size of the constituent harems ranged from 3.6 to 13.4 adults $(n=4$ harems censused over a period of $>2$ consecutive reproductive periods; median $=6$ $13, \mathrm{CV}=106.7-119.9$ ). The size variation of the colony as a whole was 3.3-3.7 times less than that of the constituent harems, and suggests that fluctuations in harem size are primarily attributable to transient movements of females between harems in adjacent roosts rather than transfers between colonies.

A single colony may consist of a single harem or several adjacent harems (Table 4), and in either situation, satellite males may or may not be present within the same colony. Because male-male competition might be expected to produce a more even distribution of reproductive females among harems, especially during periods of mating activity (cf. Bradbury \& Emmons, 1974), we tested the hypothesis that adjacent harems were smaller in size than solitary harems. We expected this discrepancy to be

Table 4. Summary of the size and social dispersion of the study population of Cynopterus sphinx in Pune, India. "Wet season" and "dry season" refer to the two annual parturition periods of C. sphinx occurring in July-August 1997 and March-April 1998, respectively. The data are based on complete censuses of all harems in the study area immediately following each of two consecutive parturition periods. The size of each demographic subunit of the study population is expressed as the mean number of sexually mature adults $( \pm 1 S D)$.

\begin{tabular}{|c|c|c|}
\hline & Wet season (1997) & Dry season (1998) \\
\hline Breeding sex ratio $(+: \widehat{)})$ & 3.3 & 8.1 \\
\hline Range & $3-25$ & $2-40$ \\
\hline Variance: mean ratio & 4.09 & 8.41 \\
\hline Breeding sex ratio $(+: \hat{)})$ & $3.5 \pm 1.7$ & $11.2 \pm 11.3$ \\
\hline Variance: mean ratio & 2.01 & 8.93 \\
\hline Breeding sex ratio $(+: \hat{)})$ & $5.1 \pm 3.5$ & $12.6 \pm 8.5$ \\
\hline No. of harems/colony & $1.7 \pm 0.2(1-3)$ & $1.4 \pm 0.7(1-3)$ \\
\hline No. of satellite $\widehat{\partial} \hat{o} /$ colony & $0.9 \pm 1.2(0-4)$ & $0.6 \pm 1.2(0-3)$ \\
\hline
\end{tabular}




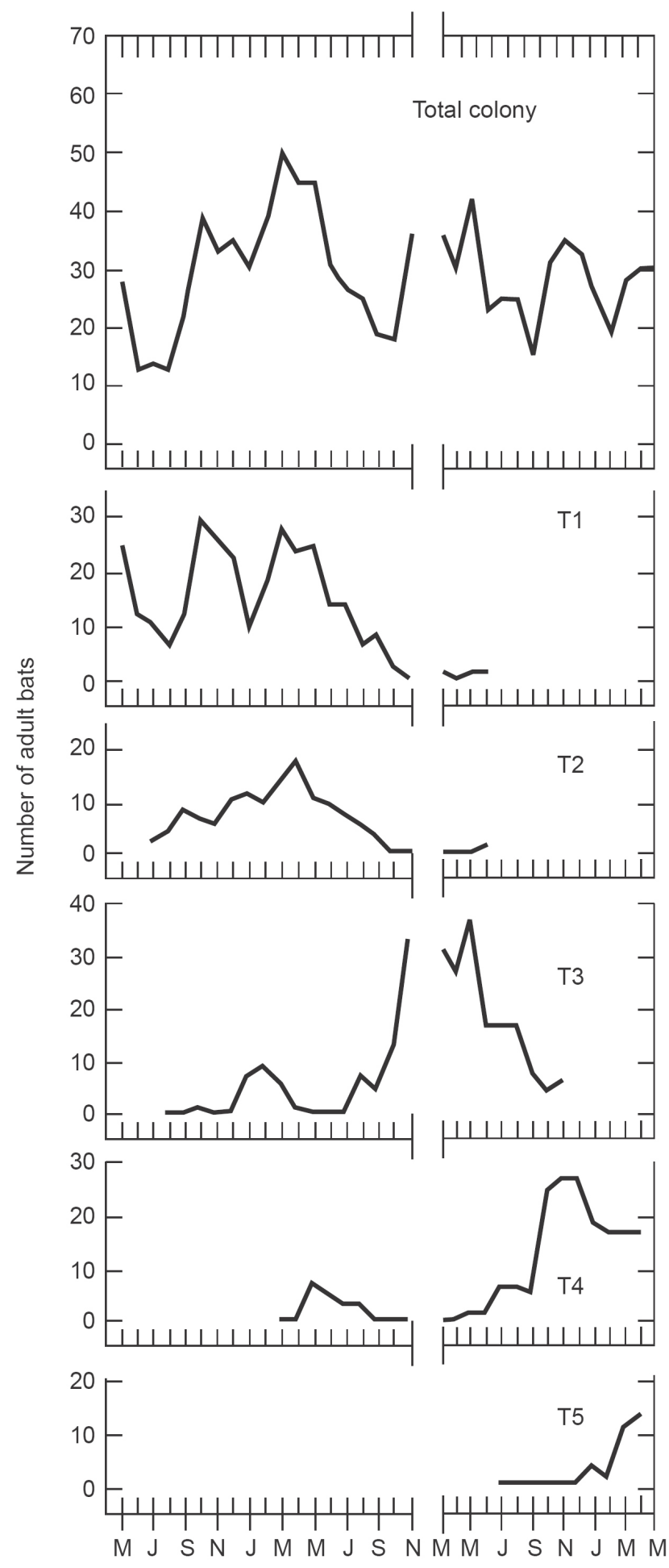

Figure 3. Temporal variation in group size of tent-roosting Cynopterus sphinx in the Mahajani colony (May 1995-April 1998). Data are based on visual censuses over a 36-month census period (minus a 3-month gap between December 1996 and February 1997). During the census period, a series of five tents (T1-T5) constructed in flower/fruit clusters on the same tree were occupied as diurnal roosts by C. sphinx. A range of one to four harems occupied adjacent tents on the same tree simultaneously. Tents were never simultaneously occupied by more than one adult male. especially pronounced during our sampling period in the dry season, which spanned the post-partum estrus period. Our data did not support this hypothesis, as no significant differences in size between solitary and adjacent harems were evident in either season (1997, Mann-Whitney $U$-test, $U_{\mathrm{n} 1: \mathrm{n} 2}=33.0_{4: 15^{\prime}}, P=0.762 ; 1998, U_{\mathrm{n} 1 \mathrm{n} 2}=11.5_{7: 7^{\prime}}$ $P=0.140$ ).

The relative proportions of nulliparous and primiparous females within harems differed between the wet and dry seasons. In the 1997 wet season collection, all of the reproductive $(n=72)$ and non-reproductive harem females $(n=9)$ were parous. In the 1996 dry season collection, five of 43 harem females (11.6\%) were sexually mature yearlings. Four were primiparous and the remaining one was non-reproductive (neither pregnant nor lactating). In the 1998 dry season collection, 19 of 153 harem females $(12.4 \%)$ were sexually mature yearlings. Eleven were primigravid, seven were primiparous, and one was non-reproductive. Assuming that the rate of juvenile recruitment is inversely proportional to the rate of adult survivorship (Bradbury \& Vehrencamp, 1976), the combined proportion of nulliparous and primiparous females within harems at the time of parturition indicates an annual survivorship of $88 \%$ for adult females.

\section{Dispersal and group stability}

Visual censuses 1.5-2 months after the onset of parturition revealed that all juveniles dispersed from their natal harems. The natal dispersal of both sexes is also in accord with the fact that harem group membership seems to be exclusively restricted to sexually mature adults and dependent young (Table 1). In the 1997 wet season, juvenile bats born in the previous March-April parturition period were never found in harems. This same pattern of harem group composition holds true in C. sphinx populations sampled throughout peninsular India (Storz et al., 2000). During the post-weaning/prereproductive period we often observed juveniles of both sexes roosting singly or in pairs in the unaltered foliage of various species of trees or hanging vines.

Of the 40 pups banded in 1996, none was recaptured subsequently in 1997 or 1998. Likewise, of the 67 pups banded in 1997, none was recaptured in 1998. The 19 yearling harem females sampled in 1998 that were classified as either nulliparous or primiparous (Table 1) were previously unmarked. Since these bats were born in either the March-April or July-August parturition periods of 1997, they either went unsampled during the 1997 collection or immigrated from outside the study area. Although the absence of recaptures of individuals marked as pups may indicate that juveniles dispersed beyond the boundaries of our study area (or simply went unsampled within the study area), it may also reflect a generally low rate of juvenile survivorship, as suggested by the low annual rate of recruitment of nulliparous females $(12 \%)$.

Of the 234 adult females banded in 1996 and 1997, 28 were recaptured in 1998. Eight (28.6\%) were recaptured 
in their original roosts, $18(64.3 \%)$ were recaptured in different roosts within the original colony, and two (7.1\%) were recaptured in a different colony. Thirteen females remained in the same colony with the original harem male from the previous parturition period, and only one female was recaptured in the same roost with the original harem male. In the transition from one reproductive period to the next, subsets of harem females remained associated as roostmates. For example, four of the eight females originally captured in tent $\mathrm{T} 2$ of the Ranade colony were found roosting together during the following reproductive period in the adjacent tent $\mathrm{T} 4$ with a new, unmarked harem male and five unmarked females. At the same time, T2 was occupied by a single nulliparous female and the male who had roosted singly in tent T3 the previous year. This fissioning of harems was especially pronounced following the complete abandonment of a tent. Of those groups that disbanded, subsets of the original group were often found roosting together in an adjacent tent in the same colony. For example, of the 16 adult females captured in tent T3 of the Mahajani colony in 1997, six were recaptured in different roosts of the same colony in 1998 after T3 had been completely abandoned. Five females were found roosting in T4 with a new (and unmarked) harem male and 11 other females, two of which were original residents of the same tent from 1997 and the remainder were unmarked. The other female from T3 was found roosting in T5 with seven unmarked females and the harem male who had roosted in T4 the previous year. Of those groups that were founded during our period of observation, the roosts were always occupied by a single adult male for several weeks or months before the arrival of any females. Of the six harem males banded in 1996, one was recaptured 15 months later (in July 1997) with a harem of previously unmarked females in a different tent in the original colony (Gaikwad). The tent in which he was originally captured had since deteriorated and was completely abandoned. Thus, at least some harem males may retain breeding tenure for as many as four consecutive reproductive periods. Of the 16 males originally banded in 1997, four were recaptured in their original colonies in 1998: two harem males were still defending harems, one harem male had become a satellite male, and one satellite male had become a harem male. In the eight roosts in which bats were sampled in successive parturition periods, seven males were replaced and one male retained his original position. The mark-recapture data thus indicate that both females and males remain faithful to particular colonies, but often switch roosts within the same colony from one breeding period to the next. Harem females may maintain long-term behavioral associations with one another, but the comparatively rapid turnover rate for harem males indicates that long-term mating bonds are unlikely to occur. The breeding tenure of harem males in any one particular roost is often relatively short, though some males succeed in maintaining harems sequentially in different roosts within the same colony.
Formation of new harems

In 1997-98, 24 roosts were occupied by bats in one or both years. In this transition from one parturition period to the next, eight roosts remained occupied by harems (with considerable turnover in group composition), 10 groups disbanded, and six groups were newly formed. Among those groups that disbanded, the original roost remained occupied by a single male in two cases, while in the others the roost was completely abandoned. The complete dissolution of tent-roosting groups followed the physical deterioration of six of eight tents. Two tents were completely abandoned even though they were not structurally compromised in any obvious way, and two building roosts were completely abandoned. The abandonment of these roosts may have been caused by attacks from predators such as jungle crows Corvus macrorhynchos, house crows C. splendens, rat snakes Ptyas mucosus, or spectacled cobras Naja naja, all of which are known or suspected to prey upon day-roosting C. sphinx. Although tent-roosting groups are more likely to be susceptible to predation by snakes, it is our impression that bats in building roosts are much more susceptible to attacks by crows, which are likely to be the most important predators of C. sphinx and other relatively small-bodied bats that roost in foliage or other semi-exposed situations. It is not clear to what extent group size might influence susceptibility to predation.

The mode of new group formation determines the agecomposition and degree of genetic relatedness within social groups. To assess the potential population-level consequences of group turnover, it is necessary to determine the extent to which the formation of new groups involves behaviors distinct from the recurrent intergroup exchange of breeding females. We used mark-recapture data and relative age estimates to address the following questions. Are new groups formed when nulliparous females of the same age cohort join a previously solitary male? If so, are those same-age females drawn from a single harem cohort or many? Are new harems formed when parous females join a previously solitary male? If so, are those females drawn from a single established harem or many? In many species of group-living social mammals, aggressive behavior by resident females prevents the recruitment of new females into established groups. Thus, when females disperse from their natal groups, they can join the breeding population only by jointly founding new groups. This does not seem to have happened in the C. sphinx study population. Nulliparous and primiparous females were often present in harems that had already been established for several breeding periods (Table 1). Furthermore, recapture data indicate that new harems are most often formed when parous females from an established harem join a previously solitary male in a different roost within the same colony. In 1998, three newly formed harems contained females who had been members of a harem in an adjacent tent during the previous parturition period. 


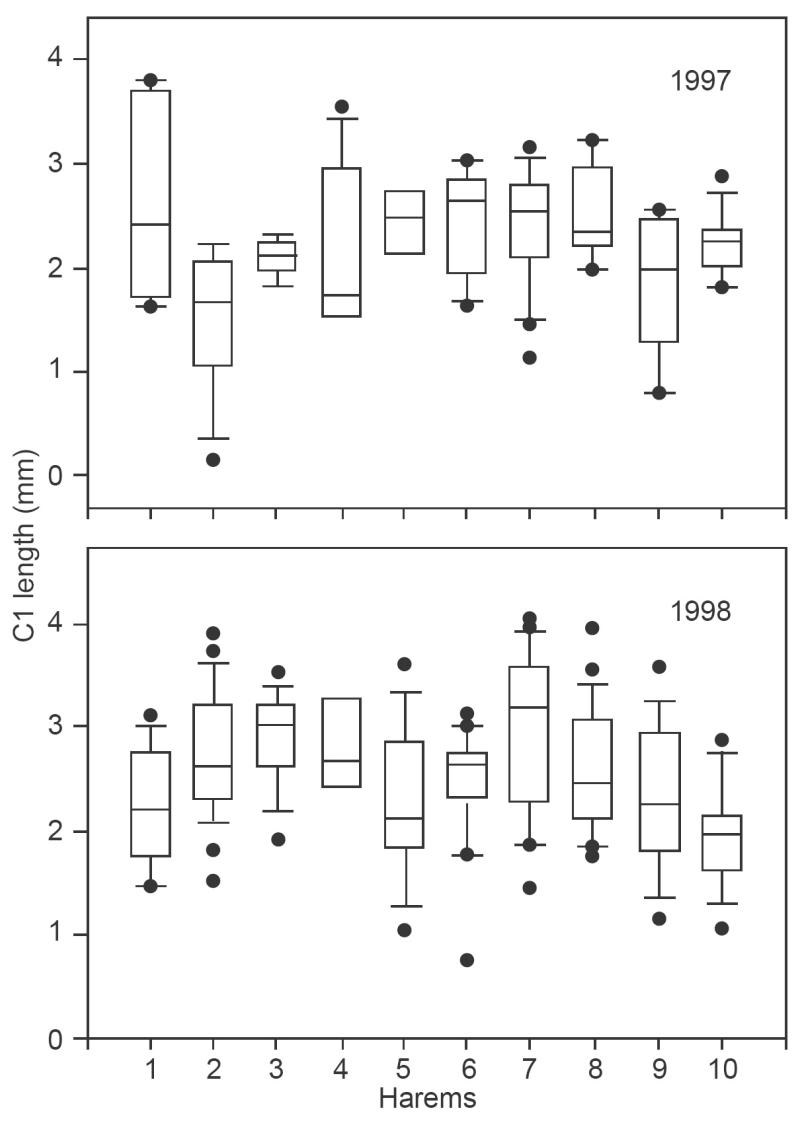

Figure 4. Box plots depicting the age composition of adult female C. sphinx within harems, based on C1 toothwear measurements (see text for details). Horizontal lines mark median $\mathrm{C} 1$ lengths, box boundaries mark the 25 th and 75 th percentiles, error bars mark the 10th and 90th percentiles, and filled symbols denote outlying values. Data are shown for each harem in which relative age estimates were obtained for $\geq 4$ adult females. In the 1997 wet season (a), harem 1 was newly established at the time of sampling and harems 2-10 were previously established (see text). In the 1998 dry season (b), harems 1-5 were newly established at the time of sampling and harems 6-10 were previously established.

These females comprised $37.5 \%, 22.2 \%$, and $44.4 \%$ of the total female group size in each of the newly formed harems (T11/Kanitkar, T5/Mahajani, and T4/Ranade, respectively), indicating that the fissioning of harems often entails the founding of a new harem within the same colony. If the formation of new harems simply results from an extension of the normal intergroup movements of females within and among colonies, the composition of harems should be random with respect to reproductive status and age.

Variation in age composition among harems (Figure 4) was assessed by testing for equality of median C1 measurements. The degree of heterogeneity was statistically significant in the 1998 dry season (Kruskal-Wallis test, $H_{\mathrm{df}}=24.603{ }_{9}, P=0.003$ ), but not in the 1997 wet season $\left(H_{\mathrm{df}}=13.036_{9}, P=0.161\right)$. If young females are primarily responsible for founding new groups, this heterogeneity in age composition in the 1998 dry season should reflect the presence of a disproportionate number of individuals with high $\mathrm{C} 1$ ranks in more recently formed harems. Although the continued exchange of adult females among groups would be expected partly to obscure the pattern, newly formed groups should contain a disproportionate number of young females, and long-established groups should be skewed toward older age classes. This was tested by performing two non-parametric, planned comparisons of age composition: (1) harems in newly created tents $v s$. harems in established roosts and (2) the founder harem of the Bhatawadekar colony vs. harems in previously established colonies. Newly created tents are defined as those in which the resident harem has undergone no more than one breeding period since the tent was first occupied. Established roosts are defined as those in which the resident harem has potentially undergone two or more breeding periods since the roost was first occupied (Table 1). This latter category includes all tents in kitul palm colonies that were first occupied by a harem before the 1997 wet season parturition period, as well as all roosts in building colonies. The harem in tent $\mathrm{T} 1$ of the Bhatawadekar colony was the founding harem of the entire colony, and was contrasted against the remaining harems occupying roosts in previously established colonies. Contrary to expectations, the contrasts revealed no significant differences in $\mathrm{C} 1$ ranks: harems in newly created tents vs harems in previously established roosts (Dunn's Post-hoc test, $Q_{\mathrm{n} 1: \mathrm{n} 2}=0.053_{30: 121}, P>$ 0.05); founder harem of the Bhatawadekar colony vs. remaining harems in previously established colonies, $\left(Q_{\mathrm{n} 1:}\right.$ $\left.\mathrm{n} 2=0.365_{34: 117}, P>0.05\right)$. It thus appears that the age composition of harems is largely unrelated to the age-stratification of the roosts they occupy. Although the formation of new harems may be non-random with respect to the age of the founding members, founding events are not restricted to newly created tents and may often involve the recolonization of previously occupied roosts. Consequently, the time since the original founding of a given roost is not an accurate predictor of the age composition of the resident harem. Although many harems are slightly skewed toward older or younger age classes, non-parametric multiple contrasts (Zar, 1999) revealed no significant pairwise differences when harems with the highest (T12/Gaikwad) and lowest (W2/Patwardhan) median C1 ranks were contrasted against all remaining harems in the 1998 dry season $\left(S_{\mathrm{n} 1 \mathrm{n} 2}=-0.585_{16: 135}, P>\right.$ 0.05 , and $S_{\mathrm{n} 1 \mathrm{n} 2}=1.008_{11: 64}, P>0.05$, respectively).

\section{Discussion}

\section{The social mating system}

The abundance and dispersion of diurnal roosting sites in the study area indicate that forced aggregation due to a limited availability of roosts is not sufficient to explain the clustering behavior of females (Figure 2). Whatever 
the underlying causes of female gregariousness, the tight clustering of reproductive females in confined roosting spaces appears to facilitate their exclusive defense by single males. The fact that males occupy roosts even in the absence of females suggests that male mating strategies are primarily based on the territorial defense of particular roosts, rather than the direct defense of compositionally labile female groups.

Polygynous mating in single male/multi-female groups is an extremely common mating system in bats (McCracken \& Wilkinson, in press), although the nature of social relationships within such groups varies across species, and across different ecological contexts within species. Much of the variation in the form of polygynous mating systems in bats can be attributed to variation in the behavioral cohesiveness of reproductive females. At one end of the spectrum are species such as Pipistrellus nanus (Happold \& Happold, 1996) and Miniopterus minor (McWilliam, 1990), in which single males establish territories and are briefly visited for mating by itinerant females. These territorial males may have simultaneous and sequential contact with a large pool of potential mates, but individual associations are highly transient. In contrast, in species such as Phyllostomus hastatus (McCracken \& Bradbury, 1981), Noctilio leporinus (Brooke, 1997), and Tadarida pumila (McWilliam, 1988), single males defend highly stable groups of reproductive females characterized by longterm affiliative relationships.

Mark-recapture data indicate that adult female $C$. sphinx frequently remained associated with one another from one parturition period to the next, either in the same roost or in different roosts in the same colony. Despite the apparent cohesiveness of subsets of harem females, recapture records indicate that the overall compositional stability of harems is relatively low. In addition to the transfers of harem females among roosts, entire harems periodically dissociate and recombine. The relatively low recapture rate for adults of both sexes in 1997 and 1998, and the large proportion of previously unmarked bats in the same collections, indicated substantial levels of immigration and emigration across the boundaries of the study area.

The fluidity of group composition was also reflected in the temporal variation in harem size in the Mahajani colony (Figure 3). A similar degree of group compositional stability was observed in tent-roosting C. sphinx in southern India (Balasingh et al., 1995; Storz et al., 2000). During observation in the March-April parturition period and the subsequent weaning and dispersal of juveniles, six adjacent tent-roosting harems ranged in size between two and 19 adult females per male. Day-to-day fluctuations in harem size indicated frequent transfers of females among tents (Balasingh et al., 1995).

One of the most striking features of the social structure of the C. sphinx study population is the highly skewed, female-biased breeding sex ratio. The apparent discrepancies in male access to reproductive females indicate the potential for an extremely high within-season variance in male reproductive success. However, even if harem size is positively correlated with male mating success within a given breeding period, the rapid rate of harem male turnover suggests that variance in the lifetime reproductive success of males is far less than indicated by cross-sectional census data. A similarly skewed breeding sex ratio was reported for a day-roosting population of C. sphinx in central India (Sandhu, 1984; Sandhu \& Gopalakrishna, 1984). Because male and female young were observed in equal numbers, Sandhu (1984) attributed the disproportionate number of breeding females to a higher mortality rate for males. However, the composition of diurnal roosting groups within a local area does not necessarily provide an accurate demographic profile of the entire adult population. Indeed, demographic surveys based on mist-netting at foraging grounds in western India (Sreenivasan, Bhat \& Geevarghese, 1974; Bhat \& Sreenivasan, 1990) and collections of day-roosting bats in northern India (Krishna \& Dominic, 1985) revealed approx. 1:1 adult sex ratios. At a site in southern India, tent-roosting populations of $C$. sphinx exhibited a mode of harem social organization qualitatively similar to that observed in Pune, and mist-netting at foraging grounds in the immediate vicinity of tent-roosts revealed no statistically significant departures from a 1:1 adult sex ratio (Storz et al., 2000). It thus seems likely that, at any given time, harem males represent a small fraction of the total adult male population. Within a given mating period, most adult males probably roost singly in unaltered foliage.

Another striking feature of the social structure of $C$. sphinx is that the same harem social configuration is maintained year-round, despite the high degree of synchrony and seasonality in the timing of parturition. Why should harem maintenance be a year-round endeavor if opportunites for mating are limited to such sharply defined periods of the annual cycle? One possible explanation is that mating activity is spread over an extended period, so the highly synchronous timing of parturition could be achieved via sperm storage, delayed implantation, or post-implantational delays in embryonic development (Heidemann, 1988, 1989; Heideman, Cummings \& Heaney, 1993; Kofron, 1997; Heideman \& Powell, 1998). However, seasonally bimodal peaks in spermatogenic activity in males (Krishna \& Dominic, 1984; Sandhu, 1988) and the timing of conceptions in females (Krishna \& Dominic, 1983; Sandhu, 1984) indicate well-defined periods of mating for C. sphinx in peninsular India. A more likely explanation for the year-round defense of roosts (and their female occupants) by harem males is that the probability of female residence in harems during periods of sexual receptivity is enhanced by residence during the preceding periods of gestation, lactation and sexual quiescence. A similar pattern of year-round harem maintenance and seasonal breeding has been observed in several neotropical bat species (Saccopteryx bilineata, Bradbury \& Emmons, 1974; Bradbury \& Vehrencamp, 1976; Phyllosto- 
mus hastatus, McCracken \& Bradbury, 1981; Carollia perspicillata, Williams, 1986). In C. perspicillata, males defend roosting territories year-round even though they have the opportunity to participate in only one of two annual mating periods. Census data on marked individuals revealed that off-season territoriality was strongly correlated with harem size during the mating period. Thus, success in harem acquisition during the mating period was determined by the outcome of year-round competition among males to defend access to roosting sites preferred by females (Williams, 1986; Fleming, 1988).

Although unremitting competition for mates seems a likely explanation for year-round harem maintenance and roost guarding by male C. sphinx, reasons for year-round group-living are less clear for females. Females often remained associated as roostmates from one parturition period to the next, and group cohesion was unaffected by harem male turnover. As in other harem-forming bats (e.g., Phyllostomus hastatus, McCracken \& Bradbury, 1981; Carollia perspicillata, Williams, 1986), the continued association of female C. sphinx is not attributable to fidelity to the same male. However, since we observed no co-ordinated relocations of female groups between colonies, it is not clear to what extent group cohesion may be attributable to actively maintained affiliative relationships among females as opposed to fidelity to a common roost or set of roosts within a colony.

We found no correlation between male body size and potential mating success (as indicated by harem size). Of course, the validity of harem size as an indicator of male mating success cannot be verified without genetic paternity data. Even if mating activity is solely restricted to diurnal roosts, the apparent fluidity of female group composition indicates that a given harem male is unlikely to have exclusive mating access to all or even most female roostmates during a given breeding period. Nonetheless, the absence of any age- or size-related correlates of harem size contrast with the results of studies of several species of neotropical fruit bats characterized by polygynous mating systems. For example, age and body size of males were both positively correlated with harem size in cave-roosting colonies of Artibeus jamaicensis (Kunz, August et al., 1983) and Carollia perspicillata (Williams, 1986). Body size has also been interpreted as an important phenotypic correlate of male mating success in several other polygynous bat species (Tadarida pumila, McWilliam, 1988; Miniopterus minor, McWilliam, 1990). Depending on the relative importance of female choice in the mating system of C. sphinx, it may be that male mating success correlates with male phenotypic characters unrelated to overall body size, or attributes of an extended phenotype related to tent architecture (Balasingh et al., 1995; Storz et al., 2000).

\section{Seasonal variation in social organization}

Whereas males defend roosts year-round and their numbers remain more or less constant within the study area, our census data indicate that a large fraction of the adult female population disappears during the wet season parturition period. Although C. sphinx is not known to undergo seasonal migrations, females may alternate between different roosting habitats in the same local area in response to changes in access to diurnal roosts with suitable microclimates or the availability of fruit and nectar resources. A similar pattern of sex-biased seasonal movement has been observed in a breeding population of the neotropical fruit bat Carollia perspicillata (Williams, 1986; Fleming, 1988). In the tropical dry forest of Costa Rica, females of C. perspicillata alternate between different roosting colonies in the wet and dry season reproductive periods, whereas males remain at the site of a single roosting colony and defend territories year-round.

\section{Dispersal and group stability}

Independent of recapture records, two lines of evidence indicate that juveniles of both sexes disperse from their natal group (if they survive to adulthood): (1) all juveniles were absent from harem groups after weaning (typically c. 45 days after the onset of parturition), (2) sexually immature bats were never present in harems at the time of parturition. This same pattern has been observed in southern India (Balasingh et al., 1995; Storz et al., 2000) and indicates that complete dispersal of both sexes from the natal harem may be a general feature of C. sphinx social structure. Since juvenile females disperse after weaning and are never found in harems, female offspring could only be recruited into their natal groups if they eventually returned after spending their post-weaning/pre-reproductive period of maturation elsewhere. Females attain sexual maturity far earlier than males and the age at first breeding for both sexes differs for members of each of the two biannual offspring cohorts (Sandhu, 1984, 1988). In central India, females born in the March-April parturition period first conceive at the beginning of the following breeding season when they are 7-8 months old, whereas females born in the July-August parturition period first conceive midway through the following breeding season when they are 5-6 months old. Males born in the March-April parturition period are first able to mate during the autumn breeding season when they are 19-20 months old, whereas males born in the July-August parturition period are first able to mate when they are 15-16 months old (Sandhu, 1988). Thus, females who were banded as pups in 1996 could have been recruited into harems by the time we made our 1997 and 1998 collections, and females who were banded as pups in 1997 could have been recruited into harems by the time of our 1998 collection. Females who were banded as pups were never recaptured, which suggests that those that 
did manage to survive to adulthood probably dispersed outside the confines of our study area. The completeness of our sampling within the study area in 1997, and especially in 1998, suggests that the recruitment of females into their natal groups, or other groups within the study area, would have been detected had it occurred. We conclude that in this particular population of C. sphinx, females are not recruited into their natal harems, nor do they join other harems in the same colony or neighboring colonies. Thus, unlike the breeding units of many social mammals, C. sphinx harems are probably not characterized by significant levels of matrilineal relatedness. This apparent absence of female philopatry contrasts with the typical pattern in social mammals (Greenwood, 1980; Dobson, 1982; CluttonBrock, 1989a) but conforms to the pattern observed in several harem-forming, neotropical bats studied to date (Wilkinson, 1987; Fleming, 1988).

\section{Formation of new harems}

Mark-recapture records indicate that the formation of new harems often results from the fissioning of previously cohesive harems within the same colony. This mode of new group formation appears to be random with respect to the age composition of the founders. However, some harems contained disproportionate numbers of young females, as indicated by reproductive status and/or relative age estimates (e.g. T1/Bhatawadekar and T12/Gaikwad in the 1998 dry season). This pattern suggests that new groups are sometimes primarily founded by members of the same age cohort. To determine the population genetic consequences of these different modes of group formation, it will be necessary to determine the degree of randomness in the genotypic composition of the founders. The genetic composition of the founders determines the levels of genetic variance within newly formed groups, and consequently the level of among-group variance at the population level. If the founders of a new group are drawn randomly from an array of genetically distinct parent groups, genetic relatedness within the nascent group will be low. This mode of group formation may either enhance or diminish genetic subdivision, depending on the nature of the founding event (Wade \& McCauley, 1988; Whitlock \& McCauley, 1990). By contrast, if new groups form by the fissioning of formerly cohesive social groups, genetic relatedness within the daughter groups may be quite high (Smouse, Vitzthum \& Neel, 1981). The fissioning of social groups according to matrilineal relatedness has been documented in several primate societies (reviewed in Storz, 1999). The founding (or co-founding) of new harems by fission groups suggests the possibility of this phenomenon in C. sphinx. When new groups are founded by nulliparous females of the same age cohort, the potential for genetic subdivision will be greatly enhanced if the females represent the progeny of a sin- gle harem. If the degree of polygyny is high, all or most of the females will be related as paternal half-siblings. In fact, since juveniles of both sexes disperse from their natal harems, the formation of new harems by groups of paternal half-sib females may be the one avenue by which the sampling effects associated with polygynous mating can be incorporated into the adult gene pool.

\section{Comparative socioecology of the Microchiroptera and Megachiroptera}

The limited number of studies to date has revealed a wide diversity of social mating systems in the Megachiroptera (reviewed in Bradbury, 1977b; McCracken \& Wilkinson, in press), including leks (Hypsignathus monstrosus, Bradbury, 1977a) and similar forms of multi-male/multi-female mating aggregations (e.g., Epomorphus wahlbergi, Wichler \& Seibt, 1976), seasonally variable, single male/ multi-female groupings (Pteropus seychellensis, Cheke \& Dahl, 1981), year-round harems with labile composition (Cynopterus sphinx, Balasingh et al., 1995; Storz et al., 2000; this study; Pteropus mariannus, Wiles, 1987), seasonally variable, multi-male/multi-female groupings (Pteropus poliocephalus, Nelson, 1965; Martin et al., 1995), year-round multi-male/multi-female groupings (Pteropus giganteus, Neuweiler, 1969) and monogamous pairs (Pteropus samoensis, Pierson \& Rainey, 1992). Of all the species studied to date, the social structure of Cynopterus appears most similar to that of the phyllostomid fruit bats Carollia perspicillata (cf. Porter, 1979; Williams, 1986; Fleming, 1988) and Artibeus jamaicensis (cf. Morrison, 1979; Kunz, August et al., 1983; Morrison \& Handley, 1991; Kunz \& McCracken, 1996). Causal factors in this apparent convergence likely include similarities in reproduction (seasonal polyestry), social behavior (female clustering in confined roosting spaces), and various aspects of their foraging ecology that obviate seasonal migration. Although these phylogenetically distant taxa exhibit many outward similarities in terms of dispersion and grouping patterns, more detailed information about social relationships within and between the sexes is needed to evaluate the ecological determinants of social structure in each species.

\section{Acknowledgements}

We thank D. N. Deobagkar, S. R. R. Reddy, S. L. Shinde, and R. Patel for logistical help in Pune, and T. H. Fleming, P. D. Heideman, C. J. Schneider, F. E. Wasserman, and two anonymous reviewers for Journal of Zoology for comments on the manuscript. This study was funded by grants to JFS and THK from the National Geographic Society and the National Science Foundation (Dissertation Improvement Grant, DEB-9701057), grants to JFS from Sigma Xi, the American Society of Mammalogists, Bat Conservation International, and the Society for Integrative and Comparative Biology, and a grant to THK from the Lubee Foundation, Inc. 


\section{References}

Anthony, E. L. P. (1988). Age determination in bats. In Ecological and behavioral methods for the study of bats: 47-58. Kunz, T. H. (Ed.). Washington, DC: Smithsonian Institution Press.

Balasingh, J., Koilraj, J. \& Kunz, T. H. (1995). Tent construction by the short-nosed fruit bat, Cynopterus sphinx (Chiroptera: Pteropodidae) in southern India. Ethology 100: 210-229.

Bates, P. J. J. \& Harrison, D. L. (1997). Bats of the Indian subcontinent. Sevenoaks, UK: Harrison Zoological Museum.

Bhat, H. R. (1994). Observations on the food and feeding behavior of Cynopterus sphinx Vahl (Chiroptera, Pteropodidae) at Pune, India. Mammalia 58: 363-370.

Bhat, H. R. \& Sreenivasan, M. A. (1990). Records of bats in Kyasanur Forest disease area and environs in Karnataka state, India, with ecological notes. Mammalia 58: 363-370.

Bhat, H. R. \& Kunz, T. H. (1995). Altered flower/fruit clusters of the kitul palm used as roosts by the short-nosed fruit bat, Cynopterus sphinx (Chiroptera: Pteropodidae). J. Zool. (Lond.) 235: 597-604.

Bradbury, J. W. (1977a). Lek mating behavior in the hammerheaded bat. Z. Tierpsychol. 45: 225-255.

Bradbury, J. W. (1977b). Social organization and communication. In Biology of bats III: 1-72. Wimsatt, W. A. (Ed.). New York: Academic Press.

Bradbury, J. W. \& Emmons, L. H. (1974). Social organization of some Trinidad bats, I. Emballonuridae. Z. Tierpsychol. 36: 137-183.

Bradbury, J. W. \& Vehrencamp, S. L. (1976). Social organization and foraging in emballonurid bats, I. Field studies. Behav. Ecol. Sociobiol. 1: 337-381.

Bradbury, J. W. \& Vehrencamp, S. L. (1977). Social organization and foraging in emballonurid bats, III. Mating systems. Behav. Ecol. Sociobiol. 2: 1-17.

Brooke, A. P. (1997). Social organization and foraging behavior of the fishing bat, Noctilio leporinus (Chiroptera: Noctilionidae). Ethology 103: 421-436.

Cheke, A. S. \& Dahl, J. F. (1981). The status of bats on western Indian Ocean Islands, with special reference to Pteropus. Mammalia 45: 205-238.

Chesser, R. K., Rhodes, Jr., O. E., Sugg, D. W. \& Schnabel, A. (1993). Effective sizes for subdivided populations. Genetics 135: 1221-1232.

Clutton-Brock, T. H. (1988). Reproductive success. In Reproductive success: 472-485. Clutton-Brock, T. H. (Ed.). Chicago: University of Chicago Press.

Clutton-Brock, T. H. (1989a). Female transfer, male tenure and inbreeding avoidance in social mammals. Nature (Lond.) 337: 70-71.

Clutton-Brock, T. H. (1989b). Mammalian mating systems. Proc. R. Soc. Lond. B Biol. Sci. 236: 339-372.

Clutton-Brock, T. H. (1991). The evolution of sex differences and the consequences ofpolygyny in mammals. In The development and integration of behavior: 229-253. Bateson, P. (Ed.). Cambridge: Cambridge University Press.

Davies, N. B. (1991). Mating systems. In Behavioral ecology: an evolutionary approach: 263-294. Krebs, J. R. \& Davies,
N. B. (Eds). Oxford: Blackwell Scientific.

Dobson, F. S. (1982). Competition for mates and predominant juvenile male dispersal in mammals. Anim. Behav. 36: 1626-1645.

Emlen, S. T. \& Oring, L. W. (1977). Ecology, sexual selection, and the evolution of mating systems. Science 197: 215-223.

Fleming, T. H. (1988). The short-tailed fruit bat: a study in plant-animal interactions. Chicago: University of Chicago Press.

Goodwin, R. E. (1979). The bats of Timor: systematics and ecology. Bull. Am. Mus. nat. Hist. 163: 73-122.

Greenwood, P. J. (1980). Mating systems, philopatry, and dispersal in birds and mammals. Anim. Behav. 28: 1140-1162.

Happold, D. C. D. \& Happold, M. (1996). The social organization and population dynamics of leaf-roosting banana bats, Pipistrellus nanus (Chiroptera, Vespertilionidae), in Malawi, east-central Afric. Mammalia 60: 517-544.

Heidemann, P. D. (1988). The timing of reproduction in the fruit bat Haplonycteris fischeri (Pteropodidae): geographic variation and delayed development. J. Zool. (Lond.) 215: 577-595.

Heidemann, P. D. (1989). Delayed development in Fischer's pygmy fruit bat, Haplonycteris fischeri, in the Philippines. J. Reprod. Fertil. 85: 363-382.

Heidemann, P. D. \& Powell, K. S. (1998). Age-specific reproductive strategies and delayed embryonic development in an Old World fruit bat, Ptenochirus jagori. J. Mammal. 79: 295-311.

Heidemann, P. D., Cummings, J. A. \& Heaney, L. R. (1993). Reproductive timing and early embryonic development in an Old World fruit bat, Otopterus cartilagonodus (Megachiroptera). J. Mammal. 74: 621-630.

Kofron, C. P. (1997). Reproduction of two species of congeneric fruit bats (Cynopterus) in Brunei, Borneo. J. Zool. (Lond.) 243: 485-506.

Krishna, A. \& Dominic, C. J. (1983). Reproduction in the female short-nosed fruit bat Cynopterus sphinx (Vahl). Period. Biol. 85: 23-30.

Krishna, A. \& Dominic, C. J. (1984). Reproductive cycle in the male fruit bat Cynopterus sphinx (Vahl 1797). Lynx 22: 19-26.

Krishna, A. \& Dominic, C. J. (1985). Observations on the social organization and sex ratio in three species of Indian bats. J. Bombay nat. Hist. Soc. 82: 24-29.

Kunz, T. H. (1996). Methods for marking bats. In Measuring and monitoring biological diversity: standard methods for mammals: 304-310. Wilson, D. E., Cole, F. R., Nichols, J. D., Rudran, R. \& Foster, M. S. (Eds). Washington, DC: Smithsonian Institution Press.

Kunz, T. H., August, P. V. \& Burnett, C. D. (1983). Harem social organization in cave roosting Artibeus jamaicensis (Chiroptera: Phyllostomidae). Biotropica 15: 133-138.

Kunz, T. H., Fujita, M. S., Brooke, A. P. \& McCracken, G. F. (1994). Convergence in tent architecture and tent-making behavior among neotropical and paleotropical bats. J. Mammal. Evol. 2: 57-77.

Kunz, T. H. \& McCracken, G. F. (1996). Tents and harems: apparent defense of foliage roosts by tent-making bats. J. Trop. Ecol. 12: 121-137. 
Martin, L., Kennedy, J. H., Little, L., Luckhoff, H. C., O’Brien, G. M., Pow, C. S. T., Towers, P. A., Waldron, A. K. \& Wang, D. Y. (1995). The reproductive biology of Australian flying foxes (genus Pteropus). In Ecology, evolution and behavior of bats: 167-184. Racey, P. A. \& Swift, S. M. (Eds). Oxford: Clarendon Press.

McCracken, G. F. \& Bradbury, J. W. (1981). Social organization and kinship in the polygynous bat, Phyllostomus hastatus. Behav. Ecol. Sociobiol. 8: 11-34.

McCracken, G. F. \& Wilkinson, G. S. (In press). Bat mating systems. In Bat biology: reproduction. Krutzsch, P. H. \& Crichton, E. G. (Eds). San Diego: Academic Press.

McWilliam, A. N. (1988). Social organization of the bat Tadarida (Chaerephon) pumila (Chiroptera: Molossidae) in Ghana, West Africa. Ethology 77: 115-124.

McWilliam, A. N. (1990). Mating system of the bat Miniopterus minor (Chiroptera: Vespertilionidae) in Kenya, East Africa: a lek? Ethology 85: 302-312.

Morrsion, D. W. (1979). Apparent male defense of tree hollows in the bat, Artibeus jamaicensis. J. Mammal. 60: 11-15.

Morrison, D. W. \& Handley, C. O., Jr. (1991). Roosting behavior. In Demography and natural history of the common fruit bat, Artibeus jamaicensis, on Barro Colorado Island, Panama: 131-135. Handley, C. O., Jr., Wilson, D. E. \& Gardner, A. L. (Eds). Washington, DC: Smithsonian Institution Press.

Nelson, J. E. (1965). Behaviour of Australian Pteropodidae (Megachiroptera). Anim. Behav. 13: 544-557.

Neuweiler, G. (1969). Verhaltensbeobachtungen an einer Indischen Flughundkolonie (Pteropus g. giganteus Brunn). Z. Tierpsychol. 26: 166-199.

Nunney, L. (1993). The influence of mating system and overlapping generations on effective population size. Evolution 47: 1329-1241.

Pierson, E. D. \& Rainey, W. E. (1992). The biology of flying foxes of the genus Pteropus: a review. In Pacific Islands flying foxes: proceedings of an international conservation conference: 1-17. Wilson, D. E. \& Graham, G. L. (Eds). Washington, DC: U.S. Fish and Wildlife Service.

Porter, F. L. (1979). Social behavior in the leaf-nosed bat, Carollia perspicillata, I: social organization. Z. Tierpsychol. 49: 406-417.

Racey, P. A. (1988). Reproductive assessment in bats. In Ecological and behavioral methods for the study of bats: 3145. Kunz, T. H. (Ed.). Washington, DC: Smithsonian Institution Press.

Ramakrishna, P. A. (1947). Post-partum oestrus in the shortnosed fruit bat, Cynopterus sphinx. Curr. Sci. 16: 186.

Sandhu, S. (1984). Breeding biology of the Indian fruit bat, Cynopterus sphinx (Vahl) in central India. J. Bombay nat. Hist. Soc. 81: 600-611.
Sandhu, S. (1988). Observations on the reproduction and associated phenomena in the male fruit bat, Cynopterus sphinx (Vahl) in central India. J. Bombay nat. Hist. Soc. 85: 135-142.

Sandhu, S. \& Gopalakrishna, A. (1984). Some observations on the breeding biology of the Indian fruit bat, Cynopterus sphinx (Vahl) in central India. Curr. Sci. 53: 1189-1192.

Smouse, P. E., Vitzthum, V. J. \& Neel, J. V. (1981). The impact of random and lineal fission on the genetic divergence of small human groups: a case study among the Yanomama. Genetics 98: 179-197.

Sreenivasan, M. A., Bhat, H. R. \& Geevarghese, G. (1974). Observations on the reproductive cycle of Cynopterus sphinx sphinx (Vahl, 1797). J. Mammal. 55: 200-202.

Storz, J. F. (1999). Genetic consequences of mammalian social structure. J. Mammal. 80: 553-569.

Storz, J. F. \& Kunz, T. H. (1999). Cynopterus sphinx. Mamm. Species 613: 1-8.

Storz, J. F., Balasingh, J., Nathan, P. T., Emmanuel, K. \& Kunz, T. H. (2000). Dispersion and site-fidelity in a tent-roosting population of the short-nosed fruit bat (Cynopterus sphinx) in southern India. J. trop. Ecol. 16: 117-131.

Wade, M. J. \& Arnold, S. J. (1980). The intensity of sexual selection in relation to male behavior, female choice and sperm precedence. Anim. Behav. 28: 446-461.

Wade, M. J. \& McCauley, D. E. (1988). Extinction and recolonization: their effects on the genetic differentiation of local populations. Evolution 42: 995-1005.

Whitlock, M. C. \& McCauley, D. E. (1990). Some population genetic consequences of colony formation and extinction: genetic correlations within founding groups. Evolution 44: 1717-1724.

Wichler, W. \& Seibt, U. (1976). Field studies on the African fruit bat Epomorphorus wahlbergi (Sundevall), with special reference to male calling. Z. Tierpsychol. 26: 345-376.

Wiles, G. J. (1987). Current research and future management of Marianas fruit bats (Chiroptera: Pteropodidae) on Guam. Aust. Mammal. 10: 93-95.

Wilkinson, G. S. (1985). The social organization of the common vampire bat, I. Pattern and cause of association. Behav. Ecol. Sociobiol. 17: 111-121.

Wilkinson, G. S. (1987). Altruism and co-operation in bats. In Recent advances in the study of bats: 299-323. Fenton, M. B., Racey, P. \& Rayner, J. M. V. (Eds). Cambridge: Cambridge University Press.

Williams, C. F. 1986. Social organization of the bat, Carollia perspicillata (Chiroptera: Phyllostomidae). Ethology 71: 265-282.

Zar, J. H. (1999). Biostatistical analysis. Englewood Cliffs, NJ: Prentice Hall. 